\title{
Lesions of the Orbitofrontal but not Medial Prefrontal Cortex Disrupt Conditioned Reinforcement in Primates
}

\author{
Andrew Pears, ${ }^{1}$ John A. Parkinson, ${ }^{1}$ Lucy Hopewell, ${ }^{1}$ Barry J. Everitt, ${ }^{2}$ and Angela C. Roberts ${ }^{1}$ \\ Departments of ${ }^{1}$ Anatomy and ${ }^{2}$ Experimental Psychology, University of Cambridge, Cambridge, CB2 3DY, United Kingdom
}

The ventromedial prefrontal cortex (PFC) is implicated in affective and motivated behaviors. Damage to this region, which includes the orbitofrontal cortex as well as ventral sectors of medial PFC, causes profound changes in emotional and social behavior, including impairments in certain aspects of decision making. One reinforcement mechanism that may well contribute to these behaviors is conditioned reinforcement, whereby previously neutral stimuli in the environment, by virtue of their association with primary rewards, take on reinforcing value and come to support instrumental action. Conditioned reinforcers are powerful determinants of behavior and can maintain responding over protracted periods of time in the absence of and potentially in conflict with primary reinforcers. It has already been shown that conditioned reinforcement is dependent on the amygdala, and because the amygdala projects to both the orbitofrontal cortex and the medial PFC, the present study determined whether conditioned reinforcement was also dependent on one or the other of these prefrontal regions. Comparison of the behavioral effects of selective excitotoxic lesions of the PFC in the common marmoset revealed that orbitofrontal but not medial PFC lesions disrupted two distinct measures of conditioned reinforcement: (1) acquisition of a new response and (2) sensitivity to conditioned stimulus omission on a second-order schedule. In contrast, the orbitofrontal lesion did not affect sensitivity to primary reinforcement as measured by responding on a progressive-ratio schedule and a home cage consumption test. Together, these findings demonstrate the critical and specific involvement of the orbitofrontal cortex but not the medial PFC in conditioned reinforcement.

Key words: appetitive conditioning; marmoset; excitotoxic; goal-directed behavior; incentive value; second-order schedule

\section{Introduction}

Much of human behavior is controlled not only by primary reinforcers such as food, sex, and warmth but also by conditioned reinforcers that have acquired conditioned value by virtue of their association with primary reinforcers. Conditioned reinforcers not only maintain behavior over protracted periods of time in the absence of and potentially in conflict with primary reinforcement but can act themselves as goals for action. An obvious example of a powerful conditioned reinforcer is money. Typically, two distinct behavioral procedures have been used to study conditioned reinforcement in the laboratory (for review, see Mackintosh, 1974; Williams, 1994): (1) second-order schedules in which a conditioned stimulus (CS) maintains high rates of responding when there are only intermittent presentations of primary reward (Goldberg, 1973; Katz, 1979; Everitt et al., 1989; Everitt, 1990; Arroyo et al., 1998) and (2) acquisition of a new response for conditioned reinforcement (Robbins, 1976; Taylor and Robbins, 1984). Using these procedures, it has been shown that in rats, conditioned reinforcement is critically dependent on

Received July 29, 2003; revised Sept. 29, 2003; accepted 0ct. 1, 2003.

This work was supported by a Medical Research Council Career Establishment grant to A.C.R. and is a publication within the Medical Research Council Centre on Behavioural and Clinical Neuroscience. We thank Prof. T. W. Robbins for critical reading of this manuscript, Dr. R. M. Ridley for supplying the marmosets, C. H. Parkinson and R. Underwood for preparation of histological material, J. Bashford for photographic assistance, and I. Bolton and A. Newman for help with preparation of figures.

Correspondence should be addressed to Angela C. Roberts, Department of Anatomy, University of Cambridge, Downing Street, Cambridge, CB2 3DY, UK. E-mail: acr4@cus.cam.ac.uk.

Copyright $\odot 2003$ Society for Neuroscience $\quad$ 0270-6474/03/2311189-13\$15.00/0 the basolateral nucleus of the amygdala (BLA) (Cador et al., 1989; Everitt and Robbins, 1992; Burns et al., 1993; Whitelaw et al., 1996; Gewirtz and Davis, 1997; Meil and See, 1997), and this has been confirmed recently in primates in a study examining the effects of excitotoxic lesions of the amygdala on performance of a second-order schedule in marmosets (Parkinson et al., 2001).

The BLA is reciprocally connected to the prefrontal cortex (PFC), in particular the orbitofrontal cortex and the medial PFC (Amaral et al., 1992), and damage to these ventromedial regions in humans is known to disrupt social and emotional behavior (Damasio, 1994; Rolls et al., 1994; Drevets, 1995), including certain aspects of decision making (Bechara et al., 1997) such as behaviors that may depend in part on the conditioned reinforcement process. Similarly, lesions restricted to either the medial PFC or the orbitofrontal cortex in rats (Frysztak and Neafsey, 1994; Powell et al., 1994; Morgan and LeDoux, 1995; Jinks and McGregor, 1997; Gallagher et al., 1999; Baxter et al., 2000; Mobini et al., 2002; Schoenbaum et al., 2003) and monkeys (Butter et al., 1963, 1970; Iversen and Mishkin, 1970; Raleigh and Steklis, 1981; Dias et al., 1997; Wallis et al., 2000) can disrupt performance on a variety of pavlovian and instrumental discrimination tasks in which responding may also depend in part on the conditioned reinforcement process. However, the precise contribution of these distinct regions of PFC to affective behavior in general and conditioned reinforcement in particular is far from clear, and in almost no studies have the functions of medial and orbital regions been compared directly (but see Wallis et al., 2000). Thus, 
the present study determined whether the orbitofrontal and/or medial PFC were involved specifically in the conditioned reinforcement process.

\section{Materials and Methods Subjects}

Common marmosets, Callithrix jacchus, bred at the Medical Research Council breeding colony at the University of Cambridge were used in the present study. They were housed in either sibling or male-female pairs in a temperature-controlled room on a $12 \mathrm{hr}$ light/dark cycle. Males had received a vasectomy to prevent any pregnancies in their female partners. All marmosets were given $2 \mathrm{hr}$ access to water and fed $20 \mathrm{gm}$ of MP.E1 primate diet (Special Diet Services, Essex, UK) and one piece of fresh fruit after the daily behavioral testing session. The diet was supplemented on weekends with marmoset jelly (Special Diet Services), peanuts, fresh fruit, and eggs. All procedures were conducted in accordance with the United Kingdom Animals (Scientific Procedures) Act of 1986 under project license 80/01344.

\section{Apparatus}

Behavioral testing took place in a specially designed automated test apparatus situated in a sound-attenuated chamber. A detailed account of the apparatus has been given previously (Roberts et al., 1988). Briefly, the marmoset is positioned in front of a touch-sensitive video display unit (VDU). Banana milkshake, which served as the reward for the experiments, could be delivered through a licking spout located immediately in front of the VDU. Auditory stimuli were produced by two tone generators located on either side of the VDU. Control programs were written in the Arachnid control language (Cenes, Cambridgeshire, UK) on an Acorn Risc personal computer.

\section{Preliminary training}

Initially, marmosets were trained to associate presentations of a tone with the delivery of banana milkshake through the licker. The animals rapidly learned to approach the licker after presentation of the tone, indicating that the tone had become an appetitive conditioned stimulus (CS). All animals were then trained to respond to visual stimuli presented on the touch screen [for a detailed description of preliminary training, see Roberts et al. (1992)].

\section{Surgical procedures}

All animals were premedicated with ketamine hydrochloride (Vetelar; $0.05 \mathrm{ml}$ of a $100 \mathrm{mg}$ solution, i.m.; Amersham Biosciences and Upjohn, Crawley, UK) and anesthetized with saffan $(0.4 \mathrm{ml}$, i.m.; ScheringPlough, Welwyn Garden City, UK). Anesthesia was maintained with top-up doses of 0.3-0.4 $\mathrm{ml}$ of saffan every 45-60 min until the end of surgery. Surgical procedures were performed while the marmoset was held in a stereotaxic frame with specially adapted incisor and zygoma bars. Marmosets were assigned to either the control or a lesion group in balanced pairs according to presurgical response rates. A standardization technique (Dias et al., 1996) was used to determine the appropriate injection sites for each animal independently, based on the thickness of the marmoset's frontal pole. Excitotoxic lesions of the medial PFC were made by infusing $0.3-0.7 \mu \mathrm{l} /$ site of a $0.09 \mathrm{M}$ solution of quinolinic acid (Sigma, St. Louis, MO) in $0.01 \mathrm{~m}$ phosphate buffer, $\mathrm{pH} 7.0$, bilaterally into three sites. Excitotoxic lesions of the orbitofrontal cortex were made by infusing $0.4-0.6 \mu \mathrm{l} / \mathrm{site}$ of a $0.09 \mathrm{M}$ solution of quinolinic acid (as described above) bilaterally into eight sites. For all placements, infusions were made over $100 \mathrm{sec}$ through a stainless-steel cannula (30 gauge). The cannula remained in place for $4 \mathrm{~min}$, after which it was withdrawn by 1 $\mathrm{mm}$, where it remained for an additional 2 min before being slowly removed from the brain. The stereotaxic coordinates used to lesion the orbitofrontal cortex and medial PFC are described in Table 1. Shamoperated control animals received infusions of the phosphate buffer vehicle bilaterally into the orbitofrontal cortex or the medial PFC.

After surgery, all animals were administered a glucose and saline solution $(0.9 \%$ saline and $1 \%$ sucrose; $5 \mathrm{ml}$, i.p.) followed by intramuscular administration of Valium (Roche Products, Hertfordshire, UK) in the
Table 1.

\begin{tabular}{cll}
\hline AP (in mm) & LM (in mm) & $\begin{array}{l}\text { Cannula position from skull base }^{a} \text { or } \\
\text { brain surface }^{b} \text { (in mm) }\end{array}$ \\
\hline $\begin{array}{cl}\text { Orbitofrontal cortex lesion } \\
+16.00\end{array}$ & \\
+16.00 & \pm 2.0 & $0.7^{a}$ \\
+16.75 & \pm 4.5 & $0.8^{a}$ \\
+16.75 & \pm 2.5 & $0.7^{a}$ \\
+17.75 & \pm 4.0 & $0.7^{a}$ \\
+17.75 & \pm 2.0 & $0.7^{a}$ \\
+18.50 & \pm 4.0 & $0.7^{a}$ \\
+18.50 & \pm 2.0 & $0.7^{a}$ \\
Medial prefrontal cortex lesion & $0.7^{a}$ \\
+16.75 & \pm 2.0 & \\
+17.50 & \pm 1.0 & $2.6^{b}$ \\
+18.50 & \pm 0.75 & $2.6^{b}$ \\
\hline
\end{tabular}

$A P$, Anteroposterior from the interaural line; LM, mediolateral from the midline.

range $0.05-0.4 \mathrm{ml}$ as required over the first $48 \mathrm{hr}$ to suppress any epileptic seizure activity. During this $48 \mathrm{hr}$ period, marmosets were kept in a quiet, dimly lit room, and their condition was checked regularly. They were then reintroduced into their home cage, where they had ad libitum access to water and a supplemented diet for $\sim 12 \mathrm{~d}$.

\section{Histological procedures}

All monkeys were perfused transcardially with $500 \mathrm{ml}$ of $0.1 \mathrm{M}$ PBS, $\mathrm{pH}$ 7.4, followed by $500 \mathrm{ml}$ of $4 \%$ paraformaldehyde fixative administered over $\sim 10 \mathrm{~min}$. The entire brain was removed and placed in a fixative solution overnight before being transferred to a $30 \%$ sucrose solution for a minimum of $48 \mathrm{hr}$ before sectioning. The sucrose solution served as a cryoprotectant during subsequent sectioning of the brains. Coronal sections were cut on a freezing sledge microtome at a thickness of $60 \mu \mathrm{m}$. Every third section was mounted on a gelatin-coated glass microscope slide and stained with cresyl fast violet. Sections were viewed under a microscope (Aristophot; Leitz, Wetzlar, Germany) and used to identify the lesioned area, which was defined by major neuronal loss often accompanied by marked gliosis. For each marmoset, the size and extent of the lesion was schematized onto drawings of a series of coronal sections through the marmoset PFC depicting every other section. Subsequently, these drawings were overlaid, and a composite figure was produced to illustrate the cortical area that was lesioned in all animals and the areas only lesioned in some of the animals. In addition, photomicrographs of the orbitofrontal cortex and medial PFC at two different rostrocaudal levels within the PFC were taken at both high Zeiss (Oberkochen, Germany) Ultraphot II and low Leitz Aristophot magnifications from representative lesioned subjects.

\section{Experiment 1: second-order schedule of reinforcement and CS omission test}

A second-order schedule of reinforcement was used to study the ability of a CS to maintain instrumental responding using a paradigm identical to that used in a previous study examining the effects of amygdala lesions (Parkinson et al., 2001).

\section{Subjects}

Fourteen marmosets (six males and eight females) took part in this experiment (group 1). Five monkeys received orbitofrontal lesions, four monkeys received medial PFC lesions, and five monkeys received a sham control procedure.

\section{Behavioral procedures}

Second-order schedule: presurgical training. Two identical blue squares $(6 \times 6 \mathrm{~cm})$ were presented simultaneously on the touch screen; one was on the left and the other was on the right. The first response of each marmoset determined the location of the reinforced stimulus for that animal, with the nonselected stimulus subsequently designated as the control stimulus for the duration of the experiment. Initially, a single response to the reinforced stimulus resulted in the disappearance of the 
stimuli, presentation of the tone (CS+), and the simultaneous delivery of banana milkshake for a total duration of $5 \mathrm{sec}$. After the cessation of reward, there was a $1 \mathrm{sec}$ intertrial interval (ITI), and then the stimuli reappeared. After three sessions of stable responding had been achieved (deviation from the mean level of responding of $<15 \%$ ), the response requirements of the second-order schedule were increased systematically, first by increasing the number of responses required to obtain the primary reinforcer [fixed ratio (FR) $x$ ] and then by increasing the number of responses for presentation of the CS (FR $y$ ) [i.e., a second-order schedule of the type $\operatorname{FR} x(\operatorname{FR} y: S)$, where $S$ is the CS and $x$ and $y$ are variable numbers of responses].

First, marmosets had to make two responses to gain primary reinforcement, and then this was increased to three, four, and then five responses [i.e., FR2(FR1:S), FR3(FR1:S), FR4(FR1:S), and FR5(FR1:S)]. Each response resulted in the presentation of the CS, which lasted $1 \mathrm{sec}$, with the final response of each schedule yielding the CS with simultaneous delivery of primary reinforcement for $5 \mathrm{sec}$. An animal was required to perform three sessions of stable responding (as defined above) at each stage before progressing onto the next stage. Having achieved stable responding on FR5(FR1:S), the duration of availability of primary reinforcement was increased from 5 to $10 \mathrm{sec}$ to support the increased response demands that would be imposed after surgery. After an additional three sessions of stable responding on this schedule, the animals received a bilateral orbitofrontal or medial PFC lesion or sham control procedure.

Second-order schedule: postsurgical testing. After a 2 week postsurgical recovery period, marmosets were returned to the FR5(FR1:S) schedule that they were on before surgery until stable responding was reacquired for three consecutive sessions. The response demands of the secondorder schedule were then made progressively more stringent such that animals had to make an increasing number of responses for the CS, whereas the number of CS presentations required for the delivery of primary reinforcement remained at five. Hence, the response requirements for presentation of the CS increased every three sessions from FR5(FR1:S) to FR5(FR2:S) [where marmosets had to make two responses rather than one to obtain a CS (FR2:S) but still had to receive five CSs before receiving primary reward, making a total of 10 responses] and then FR5(FR3:S), FR5(FR5:S), and so on, in increments of two until a marmoset failed to complete enough responses on a schedule to earn a single primary reinforcer for three consecutive sessions. This was designated as the "break point," and the behavioral testing of the marmoset was stopped.

CS omission test. To determine to what extent the presentation of the $\mathrm{CS}+$ was supporting responding, the effects of removal of the CS+ on responding were investigated. Having reached break point on the original second-order schedule of reinforcement, marmosets were returned to FR1(FR1:S) to reinstate responding. They then followed the same training pattern that they had received originally during preoperative and postoperative acquisition of responding on the second-order schedule of reinforcement, with each animal only progressing to the next stage after they had developed stable responding (as defined previously). Marmosets progressed through the various stages of the schedule until they reached a stage whereby they were receiving $\sim 15$ CS presentations and hence three primary reinforcements in a session. This criterion was chosen to equate the number of CS presentations and primary reinforcements that each marmoset received before the CS omission test, although there may be differences in the overall level of responding across subjects. After three sessions of stable responding at this performance criterion, there were the three phases of the CS omission test. Phase 1 consisted of two sessions of baseline responding on the second-order schedule (pre-CS omission) followed by phase 2 in which, for one session only, the CS presentations were omitted, although crucially, primary reinforcement was still delivered after completion of the schedule response requirements. Phase 3 consisted of two additional sessions in which the CS was once again presented (post-CS omission). This final phase was included to demonstrate that any reduction in responding during the omission session was caused by the removal of the CS rather than by a nonspecific decline in responding across sessions.

\section{Behavioral measures}

Second-order schedule. The following measures were taken: (1) responses to the rewarded and control (unrewarded) stimulus, (2) lick latency [i.e., latency (to the nearest centisecond) to lick after reward delivery commenced], and (3) trial length [i.e., the length of time (to the nearest centisecond) from the initial presentation of the trial to the final response of that trial resulting in primary reinforcement]. For each behavioral measure, the mean of the final three sessions of each stage was calculated.

CS omission test. Mean number of responses across the two sessions of both the pre-CS and post-CS omission phases (1 and 3) were recorded along with the absolute number of responses on the omission phase (2). In addition, to control for differences in absolute levels of responding across subjects, a ratio measure was calculated whereby responding during the CS omission phase (and post-CS omission phase) was considered as a proportion of overall responding in pre-CS and CS (or pre-CS and post-CS) omission phases. For example, the ratio measure for the CS omission phase was calculated by dividing the number of responses in CS omission by the sum of the number of responses in CS omission and the mean number of responses in pre-CS omission. A ratio score of 0.5 indicated that there was no difference in responding between the CS omission and pre-CS omission phases, whereas a ratio score of $<0.5$ indicated a decline in responding in the absence of the CS.

\section{Experiment 2: progressive-ratio schedule and consumption test for primary reward}

To determine whether there was any difference between the lesioned groups in their ability to respond for primary reinforcement, in the absence of secondary or conditioned reinforcers, all animals were tested on a progressive-ratio schedule for reward. In addition, any changes in the palatability of the milkshake reward after the lesions were tested in a consumption test.

\section{Subjects}

The subjects were the same as those used in experiment 1 .

\section{Behavioral procedures}

Progressive-ratio schedule. After completion of the CS omission test of experiment 1, all marmosets were trained to respond to a novel white "bow-tie" stimulus presented in the center of the touch screen. Initially, a fixed-ratio schedule of the type FR1 was in operation, with each response to the stimulus resulting in its disappearance and the availability of $10 \mathrm{sec}$ of banana milkshake. There was a $1 \mathrm{sec}$ ITI before the stimulus reappeared. There was no explicit conditioned stimulus (i.e., tone) accompanying the reinforcement. After three sessions of stable responding had been achieved (i.e., equivalent numbers of responses per session $\pm 15 \%$ of the mean responses across the three sessions), the responses required for primary reinforcement were then increased to two, three, four, and then five (i.e., FR2, FR3, FR4, and FR5). Each response resulted in the brief disappearance of the stimulus for $0.3 \mathrm{sec}$, with the final response of the schedule resulting in the disappearance of the stimulus and the availability of primary reinforcement for $10 \mathrm{sec}$. An animal was required to perform three sessions of stable responding before progressing to the next stage. After acquisition of stable responding on FR5, the response requirements were made progressively more stringent such that animals were required to make more and more responses for primary reinforcement. Thus, the fixed-ratio schedules were increased every three sessions to $10,15,25,35$, and then in additional increments of 10 until the marmoset failed to complete enough responses on a schedule to earn a single primary reinforcer for three consecutive sessions. This was designated as break point, and testing was terminated. The incremental schedule of responding was identical to that used in the second-order schedule, except that no CS was presented.

Consumption test. After a 2 week respite from behavioral testing, the monkeys were assessed on an ad libitum consumption test of three different concentrations of banana milkshake in the home cage. Two hours before the onset of the test session, both the cage mate of the test monkey and the water bottle were removed from the home cage. Consumption tests took place in the morning, several hours before daily feeding. At the onset of the consumption test, a bottle was attached to the home cage 
containing $100 \mathrm{ml}$ of the test solution. The marmoset had access to the test solution for $60 \mathrm{~min}$. The amount that the animal drank was recorded every $20 \mathrm{~min}$. Milkshakes were presented on an ascending regime of concentration [i.e., weak $(1.65 \mathrm{gm} / 100 \mathrm{ml})$, normal $(8.25 \mathrm{gm} / 100 \mathrm{ml})$, and strong $(16.5 \mathrm{gm} / 100 \mathrm{ml})]$. The "normal" solution was the concentration used as primary reinforcement in the behavioral testing apparatus. In total, the consumption test lasted $5 \mathrm{~d}$, with test solutions presented on days 1,3 , and 5 .

\section{Behavioral measures}

Progressive-ratio schedule. The measures taken were equivalent to those used for the second-order schedule

Consumption test. For each of the three test concentrations, the volume consumed (in milliliters) within each 20 min time bin of the consumption test was recorded.

\section{Experiment 3: progressive-ratio schedule for primary reward in naive animals}

Because all of the animals in experiment 2 had received extensive training and testing on a second-order schedule before the progressive-ratio schedule, it was likely that their responding on the schedules had become rather habitual in nature and was determined as much by the context of the test apparatus as by the presence of the CS. Thus, to determine whether there was any real difference between the lesioned and control groups in their ability to respond for primary reinforcement, in the absence of conditioned reinforcers, experiment 3 examined responding on a progressive ratio for primary reinforcement in naive animals that had never made multiple responses to obtain primary or conditioned reinforcement.

\section{Subjects}

The subjects in this experiment were 13 common marmosets [eight males and five females (group 2)] that had previously only been tested on response schedules of FR1. Thus, they were naive to making high levels of responses to gain access to reward.

Four monkeys had received sham control lesions, four had received lesions of the orbitofrontal cortex, and five had received lesions of the medial PFC between 6 and 8 months previously, according to the methods described in surgical procedures. Before the testing described below, all of these animals had been tested both preoperatively and postoperatively on tests of food preference (data not shown). Thus, they had performed a series of visual discriminations in which, in any one trial, two of a possible four visual stimuli were presented on the touch screen, and a response to one or the other resulted in a specific liquid reward (e.g., black currant juice or orange juice). In total, they had performed six of these discriminations and experienced a variety of different types of liquid reward before taking part in this experiment.

\section{Behavioral procedures}

Progressive-ratio schedule. After a 2 week rest period, all animals were tested on the progressive-ratio schedule. The format of the task was identical to the progressive-ratio schedule described in experiment 1 , except that two identical green squares were presented on the left and right of the touch-sensitive VDU rather than a single stimulus placed centrally. As in the second-order schedule, the first response made by the marmoset determined which was the rewarded stimulus, whereas the other square became the control stimulus.

Unconditioned stimulus omission test. To assess the role of the primary reinforcer in controlling responding, an omission test was conducted during the progressive-ratio procedure. After three sessions of responding on $\operatorname{FR}(3)$, monkeys were tested for one session of extinction in which no reward was presented. During this session, the 10 sec periods in which milkshake had previously been available were omitted so that after three responses to the rewarded stimulus, the trial went straight into the $1 \mathrm{sec}$ ITI. The next two sessions were also run at $\operatorname{FR}(3)$ but with the reward available again, as in the preomission sessions. Animals then continued on the progressive-ratio schedule as described above.

\section{Behavioral measures}

Progressive-ratio schedule. The measures taken were identical to those used in experiment 2.
Unconditioned stimulus omission test. Omission of the $10 \mathrm{sec}$ unconditioned stimulus (US) resulted in the availability of extra time in which the monkeys could respond during the US omission session compared with the pre-US and post-US omission sessions. Therefore, to take this into account, a response rate measure (i.e., the number of responses per minute) was calculated for the omission as well as the pre-US and post-US omission sessions, only including periods of time in which a response was possible (excluding US, ITI, and $0.3 \mathrm{sec}$ after each response).

\section{Experiment 4: acquisition of a new response for conditioned reinforcement}

Although marmosets with lesions of the orbitofrontal cortex were insensitive to omission of the CS on the second-order schedule, their overall performance on the second-order schedule was intact. This is in contrast to the effects observed after lesions of the amygdala in marmosets (Parkinson et al., 2001), where insensitivity to CS omission was associated with reduced overall responding on the second-order schedule. Because responding on such schedules is controlled by both the CS and the US, it is difficult to tease apart the individual contribution of these two types of stimuli. In contrast, the acquisition of a new response procedure can measure the ability of a CS to control responding independently of any response control by the US. Thus, the following experiment examined the effects of medial PFC, orbitofrontal, and sham control lesions on performance of a discrimination paradigm in which responding to one or the other visual stimuli was only ever rewarded by an appetitive CS.

\section{Subjects}

Twelve of the subjects described in experiment 1 and 11 of the subjects described in experiment 3 took part in experiment 4 . Thus, eight subjects had orbitofrontal lesions, seven had medial PFC lesions, and eight had sham control lesions.

\section{Behavioral procedures}

Pavlovian training. In a simple pavlovian procedure, a 10 sec tone (CS+) signaled the simultaneous delivery of banana milkshake through the licking spout, whereas a $10 \mathrm{sec}$ white noise (CS-) presentation was never paired with the delivery of reward. Stimuli were presented on a double alternation sequence such that after the first stimulus was presented (stimulus A) in the session, stimuli were presented in consecutive pairs until the session terminated with a single presentation of stimulus A (i.e., A, B, B, A, A . . B, B, A). The identity of the first stimulus to be presented in any one session (i.e., CS + or CS-) was determined randomly. Using this design, the stimulus presented in the next trial could not be predicted by the stimulus presented in the current trial, because the likelihood of receiving either stimulus is 50\%. Sessions consisted of 40 trials, 20 trials of each stimulus, presented on a variable time (VT) $24 \mathrm{sec}$ schedule. Thus, on this VT schedule, stimuli were presented on average after a period of $24 \mathrm{sec}$ had elapsed since the presentation of the previous stimulus. Marmosets were maintained on this procedure until they approached the licker on $<20 \%$ of white noises (CS - ) and approached the licker on $>80 \%$ of tones (CS+) for two consecutive sessions (criterion).

Visual discrimination training. Having achieved criterion performance on pavlovian training, marmosets were then trained on a series of three novel, simple discriminations. Discriminanda consisted of two white shapes $(40 \times 40 \mathrm{~mm})$ presented simultaneously on the touch screen, one to the left and the other to the right. The position of the stimuli on the screen was determined by a pseudorandom sequence with the constraint that a stimulus never occupied the same position on the screen for more than four trials in a row. A response to the correct stimulus resulted in the disappearance of both stimuli and the immediate delivery of $10 \mathrm{sec}$ of banana milkshake through the licking spout followed by a $3 \mathrm{sec}$ ITI. No explicit conditioned stimuli accompanied the reinforcement. A response to the incorrect stimulus led to the disappearance of both stimuli and a 13 sec ITI. After the first session on each simple discrimination, a correction procedure was introduced such that an incorrect response on a trial resulted in the repeated presentation of that trial until a correct response was recorded. This was included to discourage marmosets from adopting a strategy of responding exclusively to one side of the touch screen. A 
session was terminated after 40 trials were completed or after $20 \mathrm{~min}$, whichever occurred sooner. Training on each simple discrimination continued until a criterion of at least $90 \%$ correct (i.e., 36 of 40 ) was achieved for two consecutive sessions. Having successfully achieved criterion on the first discrimination, marmosets then received an additional two discriminations, each requiring the discrimination of two novel shapes. Having achieved criterion on each, subjects were transferred to the acquisition of a new response for conditioned reinforcement task.

Acquisition of a new response for conditioned reinforcement. Two multicolored shapes (designated S+ and S-) were presented on the left and right of the touch screen. A response to $\mathrm{S}+($ or $\mathrm{S}-$ ) resulted in the brief disappearance of both stimuli from the touch screen lasting $0.3 \mathrm{sec}$ and then the reappearance of $S+($ or $S-$ ) in the same spatial location for 1 sec. In the case of a response to $S+$, its reappearance was accompanied by the presentation of the tone for $1 \mathrm{sec}(\mathrm{CS}+)$, whereas in the case of a response to $\mathrm{S}-$, its reappearance was paired with $1 \mathrm{sec}$ of white noise $(\mathrm{CS}-)$. The designation of each particular stimulus as $\mathrm{S}+$ or $\mathrm{S}-$ was counterbalanced within each group. This sequence of events was followed by a $3 \mathrm{sec}$ ITI, during which no stimuli were present on the touch screen. The left-right positioning of stimuli on the screen was determined by a pseudorandom sequence, as described for visual discrimination training. An overlying schedule of pavlovian pairings was superimposed on the session with a VT of $67.5 \mathrm{sec}$. Once this variable time had elapsed, the visual stimuli were cleared from the touch screen, and after a $5 \mathrm{sec}$ delay, a $10 \mathrm{sec}$ tone $(\mathrm{CS}+)$ or white noise (CS - ) was presented. A tone was accompanied by the simultaneous delivery of banana milkshake through the licker, whereas white noise was never accompanied by reward. These pairings were superimposed on the session according to a double alternation schedule as described for pavlovian training (e.g., $\mathrm{CS}+, \mathrm{CS}-, \mathrm{CS}-, \mathrm{CS}+, \mathrm{CS}+$, etc.). If a response was in progress when the VI elapsed, the onset of the pavlovian pairing was delayed until the beginning of the ITI that followed the response. A 5 sec ITI was always imposed immediately before a pavlovian pairing to reduce the likelihood of a reward being erroneously attributed to a response. This superimposed pavlovian schedule leading to the delivery of primary reward prevented marmosets from extinguishing their responding before they had been able to display any discrimination of the two stimuli. Thus, in this task, primary reward was still available, but crucially, it was not contingent on responding to one or the other visual discriminanda. Thus, any preferential responding to one or the other visual discriminanda was not attributable to their association with primary reward. A session ended either after $20 \mathrm{~min}$ or when 50 trials had been completed, whichever occurred first. All animals received two sessions.

\section{Behavioral measures}

Pavlovian training. An error score was calculated for each subject by summing the number of CS + trials in which there was no approach to the licker with the number of inappropriate licker approaches during $\mathrm{CS}$ - trials before reaching behavioral criterion. Any errors made on the two criterion sessions were excluded from this error score.

Visual discrimination training. The total number of errors made before reaching criterion was calculated for each subject for each discrimination. Any errors made during the two criterion sessions were excluded from this error score.

Acquisition of a new response for conditioned reinforcement. The total number of responses to $\mathrm{S}+$ and $\mathrm{S}-$ across the two sessions was calculated.

\section{Statistical methods}

All behavioral data were analyzed using SPSS for Windows (version 9; SPSS, Chicago, IL). An overall ANOVA comparing responding across all second-order schedules was not possible, because the lesion and control group sizes changed across the different schedules as individuals dropped out. Therefore, the data for the three groups at each level of the schedule [e.g., FR5(FR7:S)] were compared using independent $t$ tests adjusted for multiple comparisons (Bonferroni procedure) (Howell, 1999). Furthermore, the overall survival of animals from each group, across the secondorder schedule, was compared using Fisher's exact statistic (Siegal and Castellan, 1988). The CS omission data were analyzed using a ratio mea- sure to control for differences in baseline responding on different schedules.

A series of analyses similar to those described above were performed on the data from the progressive-ratio schedule and the US omission test. ANOVA was also used to analyze the data from the reward consumption test and the acquisition of a new response procedure. Simple main effects were used to examine any interaction effects.

\section{Results}

\section{Lesion assessment}

The extent of the orbitofrontal and medial PFC lesions is represented schematically in Figure 1, and photomicrographs of representative lesions are provided in Figure 2. These figures illustrate the regions that were consistently lesioned in all or nearly all marmosets and those that were lesioned in a minority of marmosets in the two groups of orbitofrontal-lesioned and medial PFClesioned animals. The intention was to lesion the orbitofrontal surface anterior to the genu of the corpus callosum, sparing the highly granular region on the lateral convexity (Fig. 1, inset) that we have shown to underlie dissociable behavioral processes to the orbitofrontal region (Dias et al., 1996, 1997). On the medial wall, the intention was to lesion the agranular regions that receive input from the amygdala (J. Parkinson, L. Hopewell, A. Roberts, unpublished findings) and that appear cytoarchitectonically similar to areas 25 and 32 in the rhesus monkey, as defined by Preuss and Goldman-Rakic (1991) (Fig. 1, inset). To avoid overlap between the two lesion sites, the cortex lying on the ventromedial convexity adjacent to both orbitofrontal and medial regions was not targeted intentionally.

In group 1 (experiments 1, 2, and 4), the lesion of the medial PFC extended from just posterior to the frontal pole [defined as the most anterior sector of the brain in which there is no obvious white matter underlying the dorsal, medial, and orbital surfaces (e.g., the first section on the schematic in Fig. 1, G.1, medial PFC lesion)] to just anterior to the appearance of the head of the caudate nucleus (Fig. 1, G.1). In most cases, the damage was bilateral and did not extend into the ventromedial convexity at the base of the brain (Fig. $2 A-D$ ). In three of the four medial PFC-lesioned monkeys, there was cell loss in the overlying dysgranular region (Fig. 1, sections 2 and 3, G.1) that was only bilateral in one monkey.

The lesion of the orbitofrontal cortex (Fig. 2E-H) extended from the posterior edge of the frontal pole to just posterior to the genu of the corpus callosum (Fig. 1, G.1, orbitofrontal lesion). In most cases, it included the majority of the dysgranular regions, sparing the more anterior granular regions. In four of the five animals, there was variable cell loss to the ventromedial convexity, greater anteriorly than posteriorly and greater on the left than the right. There was limited cell loss in the posterior sector of the frontal pole. One monkey had unilateral cell loss in the dorsal region of the frontal pole (Fig. 1, G.1, second section), probably as a result of the excitotoxin spreading up the cannula tract.

In group 2 (experiments 3 and 4), all four monkeys with medial PFC lesions had a lesion that extended from just posterior to the frontal pole to just anterior to the level of the genu of the corpus callosum. It included the agranular regions within the medial wall, sparing for the most part the overlying dorsomedial convexity region. In all cases, the lesion did not extend into the ventromedial convexity region. However, in one case, the lesion extended just beyond the genu of the corpus callosum (Fig. 1, G.2, medial PFC lesion).

Three of the four monkeys with orbitofrontal lesions had lesions extending from just behind the frontal pole to the level of the genu of the corpus callosum. These lesions included the ma- 
G.1 Medial PFC Lesion<smiles>C1CCCC1</smiles><smiles>C1CC2CC1C2</smiles><smiles>C1=CC(C=C2CC3CCC2CC3)=CC1</smiles>
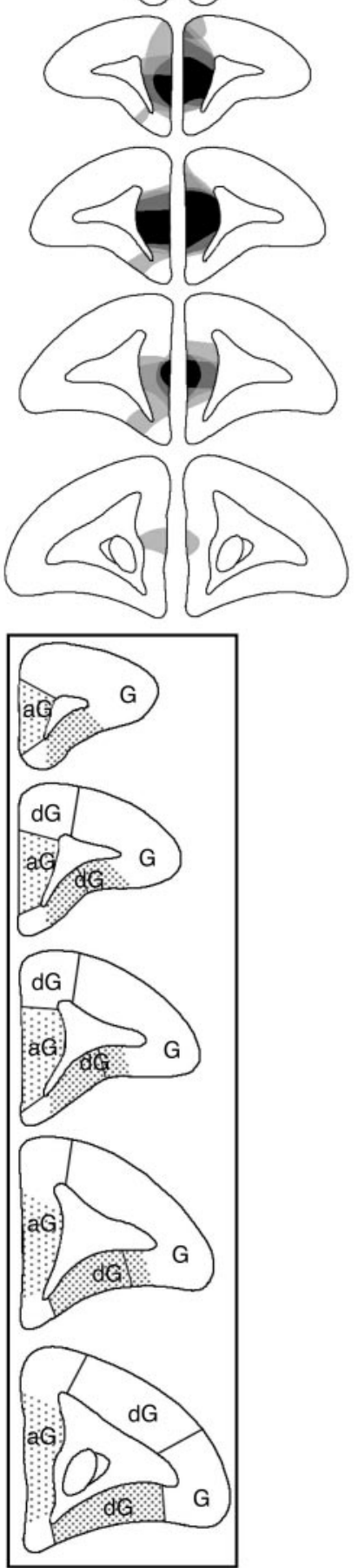

G.1 Orbitofrontal Lesion
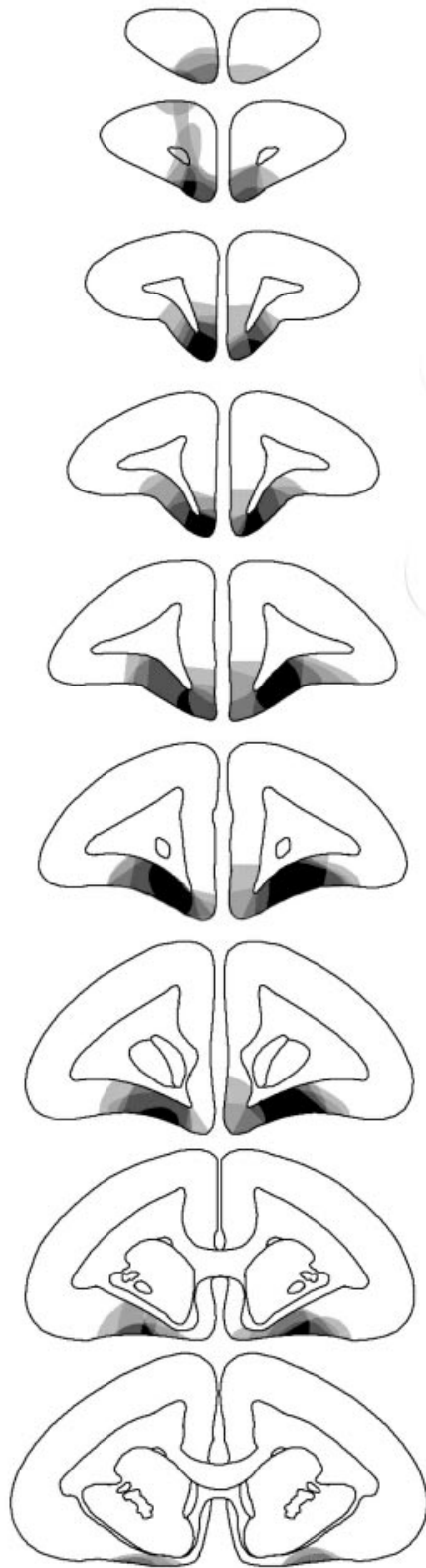

G.2 Medial PFC Lesion
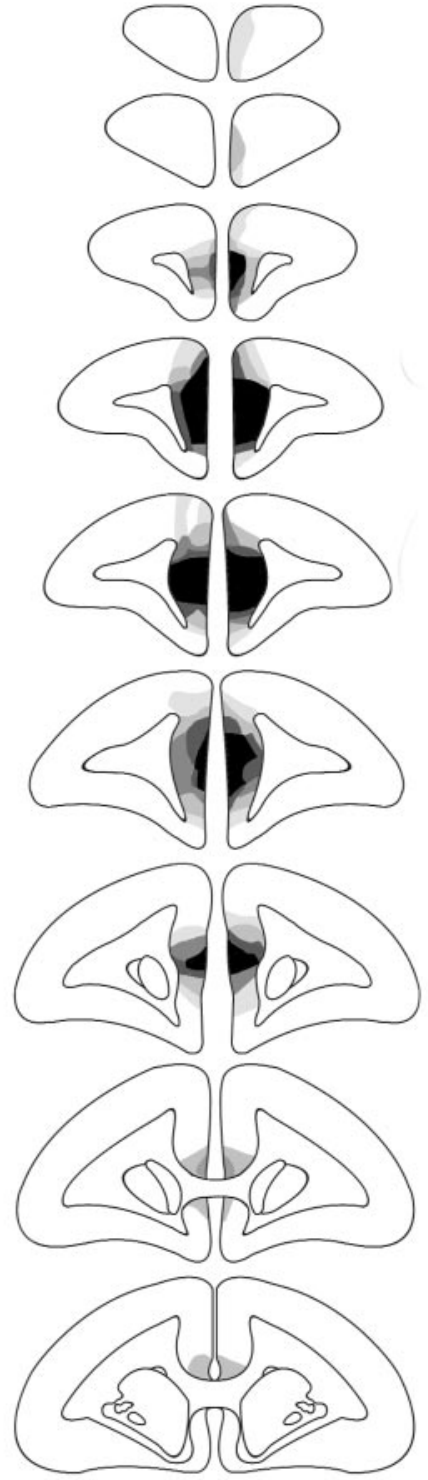

G.2 Orbitofrontal Lesion
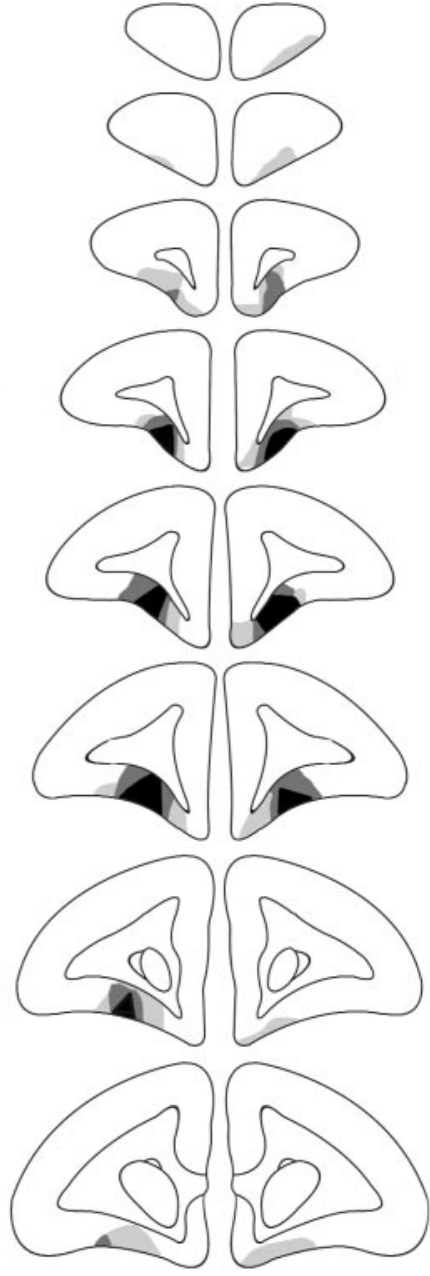

Figure 1. Schematic diagrams of a series of coronal sections through the frontal lobe of the marmoset illustrating the site of the lesion of the medial PFC and orbitofrontal lesion of group 1 (G.1) in experiments 1, 2, and 4 and group 2 (G.2) in experiments 3 and 4. The different levels of shading, ranging from solid black to pale gray, represent the areas of cortex that were damaged in all monkeys, in all monkeys but one, etc., to just one monkey, respectively. The distribution of granular (G), dysgranular (dG), and agranular (aG) regions of cortex within the frontal lobes of the marmoset are illustrated in the series of coronal sections depicted in the inset. The frontal pole is granular throughout. The shaded regions on each coronal section within the inset represent the regions on the orbital surface and the medial wall that were the targets for the orbitofrontal and medial PFC lesions, respectively. 
A
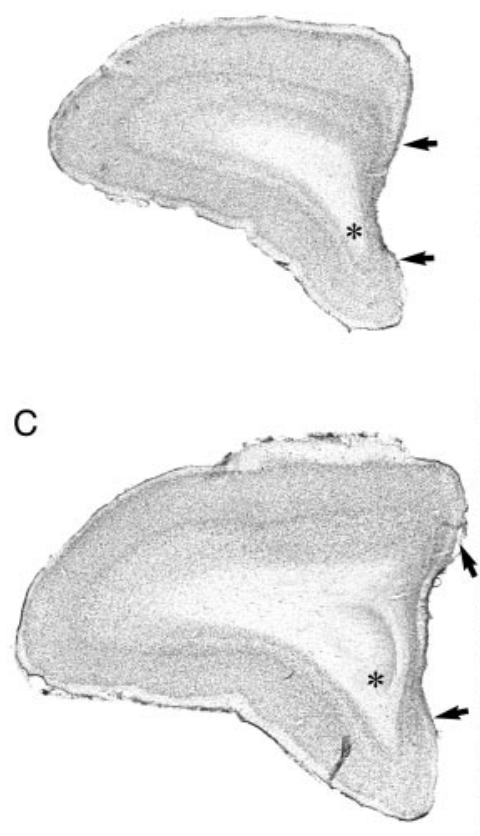

E

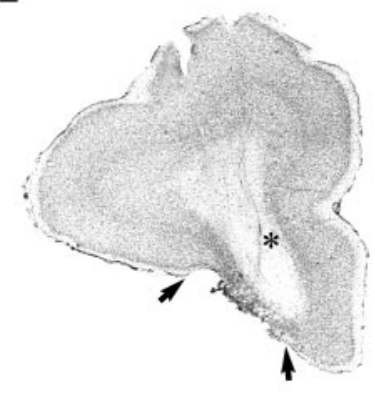

G

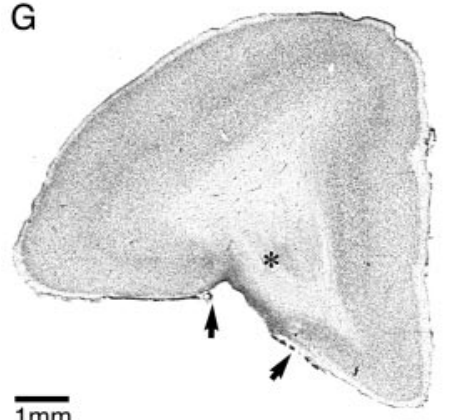

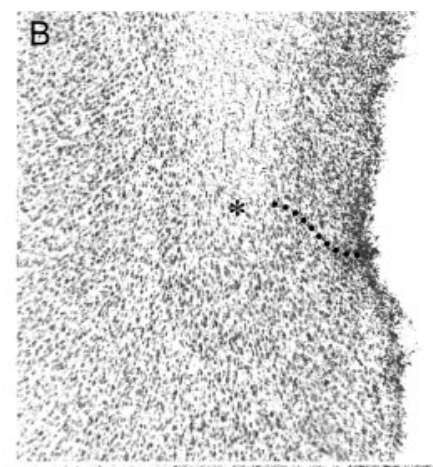
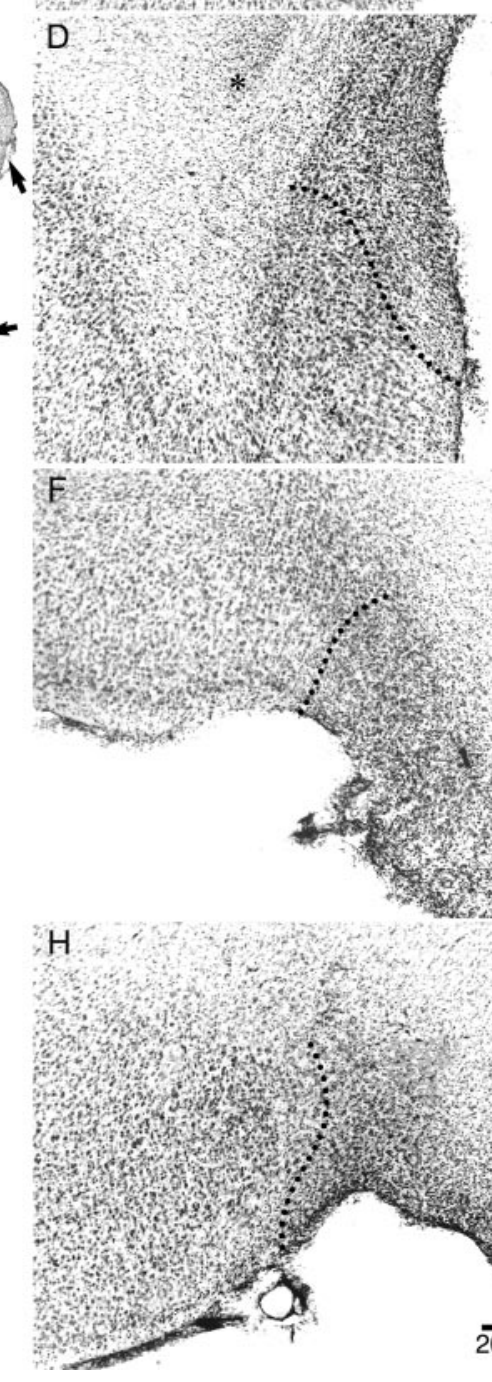

$$
20
$$

Figure 2. Low-power $(A, C, E, G)$ and high-power $(B, D, F, H)$ photomicrographs of cresyl fast violet-stained coronal sections through rostral $(A, B, E, F)$ and intermediate $(C, D, G, H)$ levels of the frontal lobe taken from a representative marmoset from the medial PFC $(A-D)$ - and orbitofrontal $(E-H)$-lesioned groups. The extensive cell loss in the lesioned areas is in stark contrast to the dense layering of neurons seen in the adjacent intact areas. In addition, the loss of orbitofrontal tissue in the orbitofrontal-lesioned monkey $(E, G)$ is in contrast to the intact orbitofrontal cortex in the medial PFC-lesioned monkey $(A, C)$ and vice versa. The arrows in $A, C, E$, and $G$ and the dotted lines in $B, D, F$, and $H$ mark the border(s) of the lesion. The asterisks mark the same position in $A, C$, $E$, and $G$ as they do in $B, D, F$, and $H$, respectively.

jority of dysgranular cortex along the orbital surface, but there was some sparing, often bilaterally, of the more anterior granular regions (Fig. 1, G.2, orbitofrontal lesion). There was also some sparing, often bilaterally, of the extreme lateral regions of dysgranular cortex at all anteroposterior levels. In the fourth orbitofrontal-lesioned monkey (data not shown in Fig. 1), cell

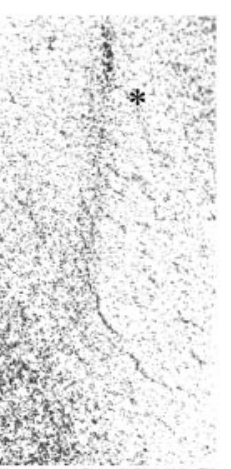

loss and gliosis were only evident on one side and were limited to a region midway between the frontal pole and the genu of the corpus callosum, sparing the anterior $800 \mu \mathrm{m}$ of cortex posterior to the frontal pole and the $500 \mu \mathrm{m}$ of cortex anterior to the genu of the corpus callosum. In addition, the lesion was restricted to the superficial layers of cortex, sparing the deep layers. Consequently, this lesion was deemed insufficient, and the animal was dropped from the orbitofrontal lesion group.

\section{Behavioral assessment}

Experiment 1: second-order schedule of reinforcement and CS omission test Second-order schedule: presurgical training. There was no difference in the presurgical level of responding between the three groups (Fig. 3A). Repeated-measures ANOVA of responses to the rewarded stimulus with a between-group factor of lesion (control, orbitofrontal, medial) and a within-group factor of schedule (FR1, FR2, FR3, FR4, FR5) over presurgical acquisition revealed a main effect of schedule $\left(F_{(2,22)}=72.748 ; p<0.001\right)$ but no effect of lesion $(F<1)$ and no lesion $\times$ schedule interaction $(F<1)$. The schedule effect was the result of an increase in responding with increasing response demands.

Second-order schedule: postsurgical testing. There were no significant differences between groups in the postsurgical reacquisition of responding on FR5(FR1:S). ANOVA comparing presurgical and postsurgical responses to the rewarded stimulus revealed no effect of lesion $(F<1)$, no effect of surgery $\left(F_{(1,11)}=2.156\right.$; NS) and no lesion $\times$ surgery interaction $\left(F_{(2,11)}=\right.$ 1.918; NS).

Initially, as the response demands of the schedule were increased, all monkeys tended to increase their responding. However, on progressively higher schedules, the responding of all monkeys started to decline such that they received progressively fewer CS presentations and consequently fewer primary reinforcers. Although there was a trend for orbitofrontal-lesioned subjects to perform more responses than control and medial PFClesioned subjects on the higher schedules, on no schedule did this reach statistical significance. Examination of the response rates of individual monkeys revealed that the overall increase in mean responding in the orbitofrontal-lesioned group was primarily attributable to two orbitofrontal-lesioned monkeys displaying consistently elevated responding across all schedules and a third monkey exhibiting elevated responding between FR5(FR5:S) and FR11(FR5:S). The responding of the other two lesioned monkeys did not differ from controls. 
Repeated-measures ANOVA of responses to the rewarded stimulus across schedules until the first subject dropped out revealed a main effect of schedule $\left(F_{(4,44)}=12.33 ; p<0.001\right)$, no effect of lesion $\left(F_{(2,11)}=1.85\right.$; NS) and no lesion $\times$ schedule interaction $(F<1)$. This schedule effect was the result of a general increase in responding across progressive schedule demands. One-way ANOVA of responses to the rewarded stimulus on each postsurgical schedule requirement, adjusted for multiple comparisons using the Bonferroni correction procedure (Howell, 1999), revealed no difference between lesion groups at any stage [the highest group difference was for FR5(FR11:S); $F_{(2,10)}=2.146$; NS]

Eventually, the demands of the schedule were such that monkeys failed to retrieve a single primary reinforcer over three consecutive sessions, at which point the behavioral testing of that marmoset was stopped. All five control monkeys, three of four medial PFC-lesioned monkeys, and three of the five orbitofrontal-lesioned monkeys failed to maintain responding on FR5(FR15:S). The remaining two orbitofrontal-lesioned monkeys failed at FR5(FR:19S) and FR5(FR21:S), respectively, and the remaining medial PFC-lesioned monkey failed at FR5(FR17:S). Fisher's exact statistic revealed no significant difference between the dropout rate of the three groups across the second-order schedule (all $p$ values $>0.05$ ), showing that there was no difference in how far each group progressed on the schedule.

A comparison of the extent and precise spatial location of the lesion in the five orbitofrontal-lesioned monkeys revealed no systematic differences between those monkeys that exhibited high responding on the second-order schedule and those that did not.

Second-order schedule: control measures. There were no differences between lesion groups for the other variables analyzed, either before or after surgery. Responding on the control stimulus was very low for all groups throughout acquisition of the second-order schedule and was not affected by the lesion [the highest group difference was for FR5(FR1:S) postsurgically; $\left.F_{(2,13)}=2.05 ; \mathrm{NS}\right]$. In addition, there was no difference between groups in the number of responses directed toward the touch screen away from the stimulus locations [the highest group difference was for FR5(FR13:S); $F_{(2,7)}=2.83$; NS], indicating that all groups were equally accurate at responding to the stimuli. The latency to collect primary reinforcement also did not differ across groups either before or after surgery (all $F$ values $<1$ ). Presurgical trial length did not differ between groups $(F<1)$, although there was a significant effect of schedule length $\left(F_{(2,22)}=56.87\right.$; $p<0.001)$, indicating that response requirements took longer to complete as they were progressively increased. Postsurgically, trial lengths increased in a relatively linear manner for all groups, and there were no differences between groups at any level of the schedule [the highest group difference was for FR5(FR11:S); $F_{(2,9)}=1.48$; NS].

Omission of CS. Having reached break point on the secondorder schedule, subjects were then gradually retrained to respond to a level at which they were obtaining approximately three primary reinforcers and therefore $\sim 15$ CS presentations. At this

\section{B. CS omission test}

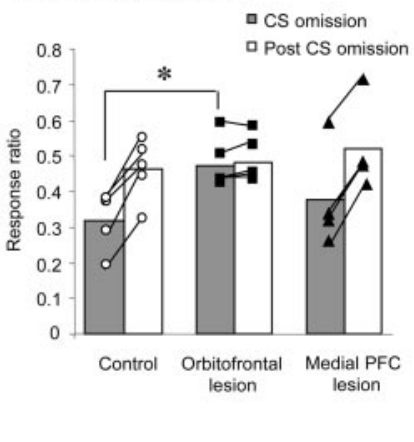

- Orbitofrontal lesion

- Medial PFC lesion

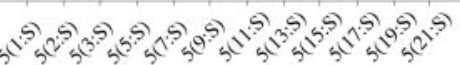

second-order schedule

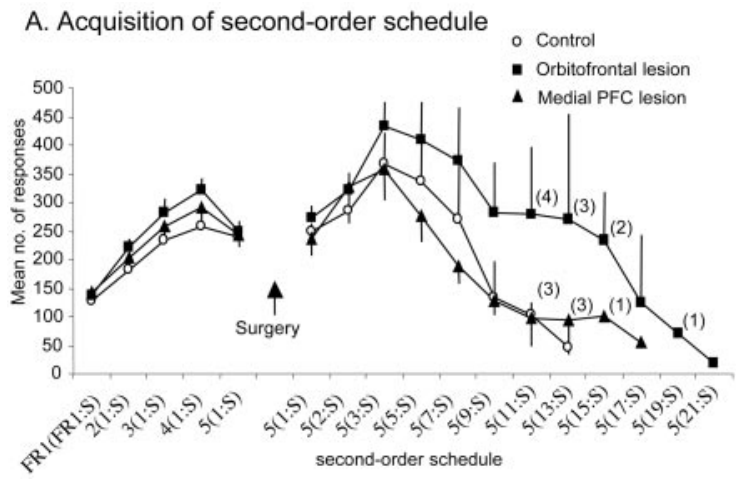

Figure 3. $A$, Mean \pm SEM number of responses at each level of the second-order schedule both before and after surgery for nimals $(n=5)$, animals with orbitofrontal lesions $(n=5)$, and animals with medial PFC lesions $(n=4)$. Numbers in the level at which seven responses are required before presentation of a CS and five such CSs must be gained, and thus a total of phases relative to the pre-CS omission phase [e.g. CS omission/(CS omission + pre-CS omission)] for the control, orbitofrontal, and medial PFC-lesioned groups. A score of 0.5 indicates that responding was equivalent to the pre-CS omission phase. Each symbol represents the ratio score of an individual animal. The asterisk indicates that the response ratio for the $C S$ omission phase in the orbitofrontal-lesioned group was significantly greater than that of the control group at $p<0.05$.

point, the effect of omitting CS presentations was assessed. After removal of the CS in the omission test, there was a marked drop in responding of the control and medial PFC-lesioned monkeys, as shown by the ratio scores well below 0.5 in Figure $3 B$, which returned to pre-CS omission levels across the following two sessions when the CS was reintroduced. In contrast, no decline in responding was observed in the orbitofrontal-lesioned group after removal of the CS; their responding remained similar to their pre-CS omission response level. ANOVA of the ratio scores for CS omission (test phase 2) and post-CS omission (test phase 3) for all groups yielded a highly significant lesion $\times$ test phase interaction $\left(F_{(2,11)}=61.33 ; p<0.001\right)$. Post hoc analysis using the Newman-Keuls test confirmed that this interaction was attributable to the higher ratio score during the CS omission phase of the orbitofrontal-lesioned group relative to that of the control group $(p<0.05)$. There were no significant differences between the ratio scores of the medial PFC-lesioned group and either of the other two groups. Although three of the four medial PFClesioned monkeys exhibited a marked decline in responding during removal of the CS equivalent to that seen in controls, the responding of one medial PFC-lesioned monkey did not decline and, if anything, increased slightly, similar to that seen in orbitofrontal-lesioned monkeys (Fig. 3B, individual values). A comparison of the lesion of this latter monkey with the lesions of the other three medial PFC-lesioned monkeys revealed no obvious differences in either the overall extent or precise location of the lesion.

To determine whether there was any relationship between an animal's sensitivity of performance to omission of the CS and its overall level of responding on the second-order schedule, these two performance measures (i.e., ratio score for the CS omission test and total responses over all schedules as a proportion of the number of schedules completed) were compared using Pearson's product correlation test. There was no correlation between these two measures (Pearson's correlation coefficient $=0.314 ; p>0.05)$. As can be seen in Figure $3 B$, all five orbitofrontal-lesioned monkeys failed to exhibit any decline in responding after omission of the CS, although they differed from one another in their overall rate of responding on the second-order schedule. 
Experiment 2: progressive-ratio schedule and consumption test for primary reward

Progressive-ratio schedule. A similar pattern of responding emerged on the fixed-ratio procedure, as was seen on the secondorder schedule of reinforcement. Initially, the responding of all three lesion groups increased as response requirements increased, but as monkeys proceeded onto more and more stringent schedules, responding started to decline. The highest mean number of responses was $520 \pm 20$ for the control group and $500 \pm 15$ for the orbitofrontal-lesioned group at FR15 and $490 \pm$ 12 for the medial PFC-lesioned group at FR25. Again, there was a tendency for orbitofrontal-lesioned monkeys to respond at a higher level than control and medial PFC-lesioned monkeys on the higher response schedules (i.e., FR55 and above), but on no schedule was there a reliable statistical difference between groups. Repeated-measures ANOVA of responding across FR schedules until the first subject dropped out revealed a main effect of schedule $\left(F_{(4,44)}=7.01 ; p<0.001\right)$ but no effect of lesion $(F<1)$ and no lesion $X$ schedule interaction $(F<1)$. One-way ANOVA of responding on each FR schedule, adjusted for multiple comparisons using the Bonferroni correction procedure, revealed no significant difference between groups at any stage (the highest group difference was for FR75; $F_{(2,9)}=6.80$; NS).

As seen on the second-order schedule, there was also no real difference between the lesion groups in how far each group progressed on the progressive-ratio schedule. Although four orbitofrontal-lesioned monkeys maintained responding on FR95 compared with two control and three medial PFC-lesioned monkeys, one monkey from each group reached FR115. The two orbitofrontal-lesioned monkeys that showed the highest numbers of responses and a break point at the highest schedules were the same two that showed this pattern on the second-order schedule. Comparing the number of monkeys that survived at each response using Fisher's exact statistic revealed no significant difference between groups (all $p$ values $>0.05$ ).

Progressive-ratio schedule: control measures. There were no differences between lesion groups for the other variables analyzed. Groups did not differ in latency to collect primary reinforcement (all $F$ values $<1$ ), in the number of responses made to the touch screen outside of the stimulus area (all $F$ values $<1$ ), or in trial length (the highest group difference was for FR45; $F_{(2,10)}=1.33$; NS).

Consumption test. It can be seen in Figure 4 that the pattern of consumption across the different test concentrations and across the three time bins was similar for the three groups. There was an overall tendency for monkeys to consume the greatest volume of liquid in the first 20 min of the test, with progressively less consumption in the second and third 20 min time bins, respectively. In addition, all monkeys showed greatest consumption of the normal concentration (i.e., the concentration used as the reward in the behavioral testing apparatus) compared with both the weak and strong concentrations.

ANOVA of amount consumed, with a between-subjects factor of lesion and within-subjects factors of concentration and time bin, revealed no main effect of lesion $\left(F_{(2,11)}=1.32\right.$; NS) or lesion $\times$ concentration interaction $\left(F_{(3,14)}=1.57 ; \mathrm{NS}\right)$. However, there was a significant main effect of concentration $\left(F_{(1,14)}=\right.$ 33.48; $p<0.001)$ that simple contrasts revealed was attributable to a greater consumption of the normal concentration compared with the weak $(p<0.01)$ or strong $(p<0.01)$ concentrations. There was also a significant main effect of time bin $\left(F_{(1,14)}=\right.$ $141.002 ; p<0.001)$ that simple contrasts revealed was attributable to increased consumption in the first $20 \mathrm{~min}$ bin of the test compared with the second $20 \mathrm{~min}$ bin $(p<0.05)$ and the third 20

\section{Consumption test}

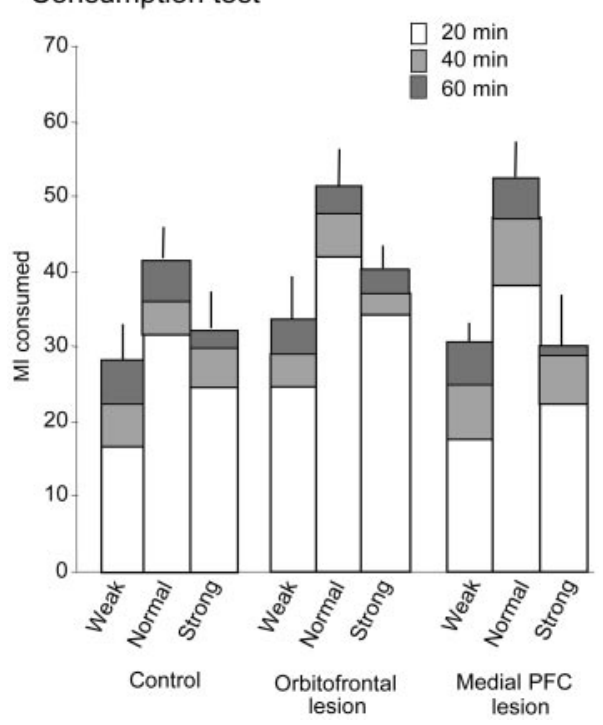

Figure 4. The cumulative mean \pm SEM volume of liquid reward consumed in the home cage across three consecutive 20 min time bins represented by the open, light gray, and dark gray sectors of the histograms, respectively, in control $(n=5)$, orbitofrontal-lesioned $(n=5)$, and medial PFC-lesioned ( $n=4)$ groups. Three different concentrations of reward were tested on different days: normal (i.e., the concentration used as reward in the test apparatus), weak (i.e., a concentration half as strong as normal), and strong (i.e., a concentration twice as strong as normal).

min bin $(p<0.05)$. There was no evidence of a time bin $\times$ lesion interaction $\left(F_{(2,14)}=3.15\right.$; NS) or a time bin $\times$ concentration $\times$ lesion interaction $(F<1)$.

\section{Experiment 3: progressive-ratio schedule for primary reward in} naive animals

The overall pattern of responding of the naive monkeys on the progressive-ratio schedule was similar to that of the monkeys in experiment 2. Initially, responding of all three groups increased as the response requirements increased, but when the monkeys reached more stringent schedules, responding started to decline (Fig. 5A). There was a marked tendency for the medial PFClesioned group to make greater numbers of responses on these higher schedules and to maintain their responding to higher response schedules than both controls and orbitofrontal-lesioned monkeys. However, comparison of the individual scores revealed that this over-responding was not a feature of the performance of all five medial PFC-lesioned monkeys. Only three monkeys exhibited this over-responding, whereas the remaining two monkeys showed comparable responding to monkeys from the other two groups. Consequently, repeated-measures ANOVA across schedules until the first subject dropped out at FR35 showed no effect of lesion $(F<1)$ and no lesion $\times$ schedule interaction $(F<$ $1)$, although there was an effect of schedule $\left(F_{(7,56)}=23.0 ; p<\right.$ 0.001). There was also no effect of lesion at each of the remaining schedules after correcting for multiple comparisons using the Bonferroni correction procedure (the highest group difference was for FR55; $F_{(2,7)}=8.040$; NS). In addition, analysis of the data by Fisher's exact statistic showed no significant difference between the survival rates of the three groups (all $p>0.05$ ).

A comparison of the extent and spatial location of the medial PFC lesion across all five lesioned monkeys did not reveal any consistent differences between those monkeys that overresponded and those that did not.

Progressive-ratio schedule control measures. Responding on the 
control stimulus increased as the response requirements increased. A repeatedmeasures ANOVA across schedules until the first subject dropped out showed a significant effect of schedule $\left(F_{(7,56)}=5.163\right.$; $p<0.01$ ), with responses to the control stimulus increasing as the response requirements of the schedules increased. There was no difference in responding between lesion groups $(F=1.3)$ and no lesion $\times$ schedule interaction $(F<1)$. There was also no effect of the lesions on the latency to retrieve a reward or the overall trial length. A repeated-measures ANOVA of lick latency and trial length across schedules until the first subject dropped out showed no difference between lesion groups $(F$ values $<1$ ) and no lesion $\times$ schedule interactions $(F$ values $<1)$. Oneway ANOVAs on each subsequent schedule revealed no significant differences between lesion groups (all $F$ values $<1$ ).

Omission of US. After three sessions of responding on FR3 of the progressive-ratio schedule, the effects of omitting the reward were assessed. During the US omission session, the rate of responding dropped in all three groups with ratio scores of $<0.5$ (Fig. 5B). During the post-US omission sessions, responding by the control and orbitofrontal-lesioned group returned to a rate of responding similar to that in the pre-US omission sessions, whereas the medial PFC-lesioned group did not, although their responding did return to pre-US omission levels $1 \mathrm{~d}$ later. A repeated-measures ANOVA on the US omission and post-US omission ratio scores revealed that there was a significant effect of test phase $\left(F_{(1,9)}=38.954 ; p<0.001\right)$, confirming that after the return of the primary reinforcer, the rate of responding increased, but there was no overall difference between lesion groups $\left(F_{(2,9)}=1.32\right)$. The strong trend toward a lesion $\times$ test phase interaction $\left(F_{(2,9)}=4.063 ; p=0.055\right)$ reflected the failure of the medial PFC-lesioned group to increase their responding on the first post-US omission session.

\section{Experiment 4: acquisition of a new response for} conditioned reinforcement

Pavlovian and visual discrimination training. There were no differences between the lesion groups in achieving criterion on the pavlovian procedure $(F<1)$. Mean errors to criterion were as follows: controls, $24 \pm 9.3$; orbitofrontal lesions, $29.57 \pm 14.2$; and medial PFC lesions, $29.9 \pm 14.3$. Similarly, there were no effects of the lesions on the number of errors to reach criterion on the subsequent series of three visual discriminations $(F<1)$. Mean errors to criterion across all three discriminations were as follows: controls, $37.5 \pm 6.4$; orbitofrontal lesions, $49.1 \pm 9.1$; and medial PFC lesions, $41.1 \pm 9.6$.

Acquisition of a new response. All animals responded to the visual stimuli on the screen, although they received no primary positive reinforcer for doing so; however, not all animals completed 50 trials during each session. It can be seen from Figure 6 that both control and medial PFC-lesioned monkeys responded preferentially to the visual stimulus that when touched, resulted in the presentation of the conditioned reinforcer (i.e., the tone that had been previously paired with reward). They made far fewer responses toward the stimulus that when touched, resulted in the presentation of the white noise (i.e., the stimulus that had

\section{B. US omission test}

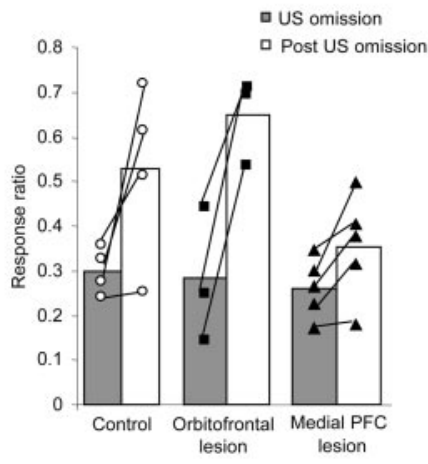
to the visual stimulus paired with the $C S$ - across the two sessions of acquisition of a new response in control $(n=8)$, orbitofrontal-lesioned $(n=8)$, and medial PFC-lesioned $(n=7)$ groups. Although the control and medial PFC-lesioned groups responded more to the stimulus paired with the $\mathrm{CS}+$ than to the stimulus paired with the $\mathrm{CS}-$, the orbitofrontal-lesioned group did not. Double and single asterisks indicate that responding to the $\mathrm{CS}+$ was significantly greater than responding to the $\mathrm{CS}-$ at $p<0.01$ and $p<0.05$, respectively.

not been paired with the reward previously). In marked contrast, the orbitofrontal-lesioned monkeys responded equally to the two visual stimuli. This was confirmed by ANOVA of the mean number of responses to the two visual stimuli across both sessions, which revealed a main effect of stimulus $\left(F_{(1,19)}=21.97 ; p<\right.$ $0.001)$ and a stimulus $\times$ lesion interaction $\left(F_{(2,19)}=4.78 ; p=\right.$ 0.02). Post hoc analysis using simple main effects revealed that although both the control $\left(F_{(1,7)}=20.33 ; p<0.01\right)$ and medial PFC-lesioned $\left(F_{(1,6)}=12.44 ; p<0.05\right)$ animals responded preferentially to the stimulus paired with the conditioned reinforcer, the orbitofrontal-lesioned animals did not $(F<1)$.

\section{Discussion}

Excitotoxic lesions of the orbitofrontal cortex in marmosets impaired the acquisition of a new response for conditioned reinforcement. Consistent with this impairment, orbitofrontallesioned monkeys were also insensitive to the omission of the CS on a second-order schedule for food reward, although they showed no concomitant reduction in responding on the secondorder schedule per se. In contrast to their insensitivity to conditioned reinforcement, their sensitivity to primary reinforcement 
appeared intact, as shown by performance comparable with that of controls on: (1) a home cage consumption test of various concentrations of the primary reward, (2) acquisition of responding on a progressive-ratio schedule for primary reward, and (3) US omission. The finding that lesions of the medial PFC were without effect on either performance of the second-order schedule or acquisition of a new response illustrates the neuroanatomical specificity of the behavioral impairments.

The failure of orbitofrontal-lesioned monkeys to acquire a new response for conditioned reinforcement is similar to the deficit seen after lesions of the basolateral amygdala in rats (Burns et al., 1993) and supports the hypothesis that the orbitofrontal cortex, along with the amygdala, contributes to the mechanism by which conditioned stimuli in the environment take on reinforcing properties and support new learning. The disruption of conditioned reinforcement also accounts for the insensitivity in responding under the second-order schedule to CS omission. This insensitivity to CS omission has already been observed in both rats (Whitelaw et al., 1996) and marmosets (Parkinson et al., 2001) with excitotoxic lesions of the amygdala. However, unlike orbitofrontal-lesioned monkeys, amygdala-lesioned animals also show a progressive impairment in responding on the second-order schedule. Thus, the intact response pattern of orbitofrontal-lesioned monkeys on the acquisition of the secondorder schedule per se is somewhat surprising and suggests that the deficits after the two lesions may be dissociable.

One simple explanation for the intact performance on the second-order schedule, despite insensitivity to CS omission, is that the orbitofrontal-lesioned monkeys were not insensitive to the conditioned reinforcing properties of the CS per se but suffered from a general loss of inhibitory control and were thus unable to suppress their responding when task parameters changed. However, such an explanation cannot account for the marked deficit in the acquisition of a new response, there being no previous response biases to inhibit. An alternative explanation appeals to the fact that second-order schedules can be controlled by both primary and conditioned reinforcement and, as a consequence of a loss of the conditioned reinforcement process in orbitofrontal-lesioned monkeys, there is a compensatory enhancement in behavioral control by the primary reinforcer. The primary reinforcer is unlikely to be perceived as more rewarding, because there was no difference between the lesioned groups and the control group in the overall volume and pattern of consumption of different concentrations of the reinforcer in the home cage. Moreover, the finding of levels of responding of orbitofrontal-lesioned monkeys that were comparable with those of control and medial PFC-lesioned monkeys under the progressive-ratio schedule for primary reward (in the absence of any explicit conditioned reinforcers) rules out the possibility that the primary reinforcer has a greater overall control of responding in the orbitofrontal-lesioned monkeys. Thus, any enhancement in response control by primary reinforcement in orbitofrontallesioned monkeys on the second-order schedule is more likely attributable to a change in the balance of response control by primary and conditioned reinforcers. This alteration in balance is probably not a consequence of impaired conditioned reinforcement per se, because it is not seen in animals with amygdala lesions in which the effects of conditioned reinforcement are also compromised. Rather, it may be a result of the loss of an active inhibitory process normally performed by the intact orbitofrontal cortex, whereby competing influences on response control by primary reinforcement are suppressed to ensure appropriate control of responding by the conditioned reinforcer.
Of relevance to the present discussion on inhibitory control was the finding that when over-responding was seen on the second-order and progressive-ratio schedules, it appeared to differ between lesion groups. Although monkeys with orbitofrontal lesions only showed over-responding on the second-order schedule, monkeys with medial PFC lesions only showed overresponding on the progressive-ratio schedule. Because these effects were not significant at the group level, any interpretation must be considered with caution, but it provides additional support to the hypothesis that although the PFC as a whole may provide inhibitory control, the functional nature of that control is regionally specific (Dias et al., 1996, 1997; Rahman et al., 1999; Roberts and Wallis, 2000; Cools et al., 2002). A likely explanation for why there are variable effects of prefrontal lesions on the performance of animals on these different response schedules is because of the multiple associations that can be formed among responses, conditioned stimuli, and primary reinforcers (for review, see Dickinson and Balleine, 1994), any one or combination of which may have greater or lesser control over responding in individual animals. Only when more specific procedures are used that target particular associative mechanisms, such as acquisition of a new response for conditioned reinforcement, can the differential contributions of brain regions to these associative mechanisms be identified. Although animals with medial PFC lesions were not impaired in tests of conditioned reinforcement (Burns et al., 1993), the tendency for these animals to show overresponding on the progressive-ratio schedule for primary reward and to take longer to return to baseline levels of responding after the reintroduction of primary reward after the US omission test (experiment 3 ) is consistent with an involvement of this region in the control of goal-directed actions by primary reinforcement (Balleine and Dickinson, 1998; Killcross and Coutureau, 2003). Indeed, the marmosets with medial PFC lesions in the present study showed a disruption of performance on a response contingency test (our unpublished findings) that was similar to that reported after medial PFC lesions in rats (Balleine and Dickinson, 1998).

The precise nature of the representation underlying conditioned reinforcement is not well understood, and thus the specific mechanisms by which the amygdala and orbitofrontal cortex contribute to conditioned reinforcement have yet to be determined. Orbitofrontal neurons have been shown to code the relative reward value of CSs (Tremblay and Schultz, 1999), and lesions of the orbitofrontal cortex and basolateral nucleus of the amygdala have been shown to disrupt the process by which a cue accesses representational information about the incentive value of the associated reinforcer and guides certain pavlovian (Hatfield et al., 1996; Gallagher et al., 1999) and instrumental (Malkova et al., 1997; Baxter et al., 2000) behaviors. Such a deficit could underlie the impaired ability of a CS to act as a conditioned reinforcer in the present study. However, an alternative hypothesis is that the CS becomes desirable in its own right independent of the specific primary reinforcer with which it is associated (Mackintosh, 1974; Dickinson and Dearing, 1979), thereby implicating the orbitofrontal cortex and amygdala in the process by which CSs can acquire general affective value.

Because both the amygdala and the orbitofrontal cortex contribute to conditioned reinforcement, the question remains as to their distinct contributions. One hypothesis is that although the amygdala enables the CS to take on reinforcing properties, the orbitofrontal cortex is necessary for the CS to become a goal for action. Support for this hypothesis comes from a study in rats in which neurons within the amygdala were shown to code the mo- 
tivational significance of a CS early in learning, before behavior was guided by the CS, whereas similar neuronal coding within the orbitofrontal cortex was only seen once behavior was guided by knowledge of the CS (Schoenbaum et al., 1998, 1999). It is also consistent with our own recent findings from a human positron emission tomography neuroimaging study in which it was shown that although the amygdala was differentially active when viewing food items from a high-incentive menu compared with a low-incentive menu regardless of whether a choice between the different items had to be made, a region within the orbitofrontal cortex was differentially sensitive to high-incentive compared with low-incentive menus only when having to select between items on the menus (Arana et al., 2003). There was no difference between the activity generated by viewing high-incentive versus low-incentive menus within this region if no decision had to be made.

In summary, this study provides evidence for the role of the orbitofrontal but not medial PFC in conditioned reinforcement. It is proposed that the orbitofrontal cortex enables stimuli in the environment that have acquired value through learning to become goals for action and in so doing, actively suppress competing influences on response control from primary reinforcement and thereby enable an individual to operate successfully in complex social situations. When the balance between the control of behavior by primary and conditioned reinforcers is altered, it may produce the impulsive behavior observed in humans with ventromedial prefrontal damage or the compulsive behavior caused by substance abuse in drug addicts (London et al., 2000; Porrino and Lyons, 2000).

\section{References}

Amaral DG, Price JL, Pitakanen A, Carmichael ST (1992) Anatomical organization of the primate amygdaloid complex. In: The amygdala (Aggleton JP, ed), pp 1-66. New York: Wiley-Liss.

Arana FS, Parkinson JA, Hinton E, Holland AJ, Owen AM, Roberts AC (2003) Dissociable contributions of the human amygdala and orbitofrontal cortex to incentive motivation and goal selection. J Neurosci 23:9632-9638.

Arroyo M, Markou A, Robbins TW, Everitt BJ (1998) Acquisition, maintenance and reinstatement of intravenous cocaine self-administration under a second-order schedule of reinforcement in rats: effects of conditioned cues and continuous access to cocaine. Psychopharmacology (Berl) 140:331-344.

Balleine BW, Dickinson A (1998) Goal-directed instrumental action: contingency and incentive learning and their cortical substrates. Neuropharmacology 37:407-419.

Baxter MG, Parker A, Lindner CC, Izquierdo AD, Murray EA (2000) Control of response selection by reinforcer value requires interaction of amygdala and orbital prefrontal cortex. J Neurosci 20:4311-4319.

Bechara A, Damasio H, Tranel D, Damasio AR (1997) Deciding advantageously before knowing the advantageous strategy. Science 275:1293-1294.

Burns LH, Robbins TW, Everitt BJ (1993) Differential effects of excitotoxic lesions of the basolateral amygdala, ventral subiculum and medial prefrontal cortex on responding with conditioned reinforcement and locomotor activity potentiated by intra-accumbens infusions of D-amphetamine. Behav Brain Res 55:167-183.

Butter CM, Mishkin M, Rosvold HE (1963) Conditioning and extinction of a food-rewarded response after selective ablations of frontal cortex in rhesus monkeys. Exp Neurol 7:65-75.

Butter CM, Snyder DR, McDonald JA (1970) Effects of orbital frontal lesions on aversive and aggressive behaviors in rhesus monkeys. J Comp Physiol Psychol 72:132-144.

Cador M, Robbins TW, Everitt BJ (1989) Involvement of the amygdala in stimulus-reward associations: interaction with the ventral striatum. Neuroscience 30:77-86.

Cools R, Clark L, Owen AM, Robbins TW (2002) Defining the neural mech- anisms of probabilistic reversal learning using event-related functional magnetic resonance imaging. J Neurosci 22:4563-4567.

Damasio AR (1994) Descarte's error: emotion, reason and the human brain. London: Picador.

Dias R, Robbins TW, Roberts AC (1996) Dissociation in prefrontal cortex of affective and attentional shifts. Nature 380:69-72.

Dias R, Robbins TW, Roberts AC (1997) Dissociable forms of inhibitory control within prefrontal cortex with an analog of the Wisconsin Card Sort Test: restriction to novel situations and independence from "online" processing. J Neurosci 17:9285-9297.

Dickinson A, Balleine B (1994) Motivational control of goal-directed action. Anim Learn Behav 22:1-18.

Dickinson A, Dearing MF (1979) Appetitive-aversive interactions and inhibitory processes. In: Mechanisms of learning and motivation (Dickinson A, Boakes RA, eds), pp 203-231. Hillsdale, NJ: Erlbaum.

Drevets WC, Raichle ME (1995) Positron emission topographic imaging studies of human emotional disorders. In: The cognitive neurosciences (Gazzaniga MS, ed) pp 1153-1164. Cambridge, MA: MIT.

Everitt BJ (1990) Sexual motivation: a neural and behavioral analysis of the mechanisms underlying appetitive and copulatory responses of male rats. Neurosci Biobehav Rev 14:217-232.

Everitt BJ, Robbins TW (1992) Amygdala-ventral striatal interactions and reward-related processes. In: The amygdala (Aggleton JP, ed), pp 401430. New York: Wiley-Liss.

Everitt BJ, Cador M, Robbins TW (1989) Interactions between the amygdala and ventral striatum in stimulus-reward associations: studies using a second-order schedule of sexual reinforcement. Neuroscience 30:63-75.

Frysztak RJ, Neafsey EJ (1994) The effect of medial prefrontal cortex lesions on cardiovascular conditioned emotional responses in the rat. Brain Res 643:181-193.

Gallagher M, McMahan RW, Schoenbaum G (1999) Orbitofrontal cortex and representation of incentive value in associative learning. J Neurosci 19:6610-6614.

Gewirtz JC, Davis M (1997) Second-order fear conditioning prevented by blocking NMDA receptors in amygdala. Nature 388:471-474.

Goldberg SR (1973) Comparable behavior maintained under fixed-ratio and second-order schedules of food presentation, cocaine injection or D-amphetamine injection in the squirrel monkey. J Pharmacol Exp Ther 186:18-30.

Hatfield T, Han JS, Conley M, Gallagher M, Holland P (1996) Neurotoxic lesions of basolateral, but not central, amygdala interfere with Pavlovian second-order conditioning and reinforcer devaluation effects. J Neurosci 16:5256-5265.

Howell DC (1999) Fundamental statistics for the behavioral sciences, pp 322-324. Pacific Grove, CA: Duxbury.

Iversen SD, Mishkin M (1970) Perseverative interference in monkeys following selective lesions of the inferior prefrontal convexity. Exp Brain Res 11:376-386.

Jinks AL, McGregor IS (1997) Modulation of anxiety-related behaviours following lesions of the prelimbic or infralimbic cortex in the rat. Brain Res 772:181-190.

Katz JL (1979) A comparison of responding maintained under secondorder schedules of intramuscular cocaine injection or food presentation in squirrel monkeys. J Exp Anal Behav 32:419-431.

Killcross S, Coutureau E (2003) Coordination of actions and habits in the medial prefrontal cortex of rats. Cereb Cortex 13:400-408.

London ED, Ernst M, Grant S, Bonson K, Weinstein A (2000) Orbitofrontal cortex and human drug abuse: functional imaging. Cereb Cortex 10:334-342.

Mackintosh NJ (1974) The psychology of animal learning, pp 233-258. London: Academic.

Malkova L, Gaffan D, Murray EA (1997) Excitotoxic lesions of the amygdala fail to produce impairment in visual learning for auditory secondary reinforcement but interfere with reinforcer devaluation effects in rhesus monkeys. J Neurosci 17:6011-6020.

Meil WM, See RE (1997) Lesions of the basolateral amygdala abolish the ability of drug associated cues to reinstate responding during withdrawal from self-administered cocaine. Behav Brain Res 87:139-148.

Mobini S, Body S, Ho MY, Bradshaw CM, Szabadi E, Deakin JF, Anderson IM (2002) Effects of lesions of the orbitofrontal cortex on sensitivity to de- 
layed and probabilistic reinforcement. Psychopharmacology (Berl) 160:290-298.

Morgan MA, LeDoux JE (1995) Differential contribution of dorsal and ventral medial prefrontal cortex to the acquisition and extinction of conditioned fear in rats. Behav Neurosci 109:681-688.

Parkinson JA, Crofts HS, McGuigan M, Tomic DL, Everitt BJ, Roberts AC (2001) The role of the primate amygdala in conditioned reinforcement. J Neurosci 21:7770-7780.

Porrino LJ, Lyons D (2000) Orbital and medial prefrontal cortex and psychostimulant abuse: studies in animal models. Cereb Cortex 10:326-333.

Powell DA, Watson K, Maxwell B (1994) Involvement of subdivisions of the medial prefrontal cortex in learned cardiac adjustments in rabbits. Behav Neurosci 108:294-307.

Preuss TM, Goldman-Rakic PS (1991) Architectonics of the parietal and temporal association cortex in the strepsirhine primate Galago compared to the anthropoid primate Macaca. J Comp Neurol 310:475-506.

Rahman S, Sahakian BJ, Hodges JR, Rogers RD, Robbins TW (1999) Specific cognitive deficits in mild frontal variant frontotemporal dementia. Brain 122:1469-1493.

Raleigh MJ, Steklis HD (1981) Effects of orbitofrontal and temporal neocortical lesions on the affiliative behavior of vervet monkeys (Cercopithecus aethiops sabaeus). Exp Neurol 73:378-389.

Robbins TW (1976) Relationship between reward-enhancing and stereotypical effects of psychomotor stimulant drugs. Nature 264:57-59.

Roberts AC, Wallis JD (2000) Inhibitory control and affective processing in the prefrontal cortex: neuropsychological studies in the common marmoset. Cereb Cortex 10:252-262.

Roberts AC, Robbins TW, Everitt BJ (1988) The effects of intradimensional and extradimensional shifts on visual discrimination learning in humans and non-human primates. Q J Exp Psychol B 40:321-341.

Roberts AC, Robbins TW, Everitt BJ, Muir JL (1992) A specific form of cognitive rigidity following excitotoxic lesions of the basal forebrain in marmosets. Neuroscience 47:251-264.

Rolls ET, Hornak J, Wade D, McGrath J (1994) Emotion-related learning in patients with social and emotional changes associated with frontal lobe damage. J Neurol Neurosurg Psychiatry 57:1518-1524.

Schoenbaum G, Chiba AA, Gallagher M (1998) Orbitofrontal cortex and basolateral amygdala encode expected outcomes during learning. Nat Neurosci 1:155-159.

Schoenbaum G, Chiba AA, Gallagher M (1999) Neural encoding in orbitofrontal cortex and basolateral amygdala during olfactory discrimination learning. J Neurosci 19:1876-1884.

Schoenbaum G, Setlow B, Nugent SL, Saddoris MP, Gallagher M (2003) Lesions of orbitofrontal cortex and basolateral amygdala complex disrupt acquisition of odor-guided discriminations and reversals. Learning Mem 10:129-140.

Siegal S, Castellan NJ (1988) Nonparametric statistics for the behavioral sciences, pp 96-104. New York: McGraw-Hill.

Taylor JR, Robbins TW (1984) Enhanced behavioural control by conditioned reinforcers following microinjections of D-amphetamine into the nucleus accumbens. Psychopharmacology (Berl) 84:405-412.

Tremblay L, Schultz W (1999) Relative reward preference in primate orbitofrontal cortex. Nature 398:704-708.

Wallis JD, Dias R, Robbins TW, Roberts AC (2000) Dissociable contributions of the orbitofrontal and lateral prefrontal cortex of the marmoset to performance on a detour reaching task. Eur J Neurosci 13:1797-1808.

Whitelaw RB, Markou A, Robbins TW, Everitt BJ (1996) Excitotoxic lesions of the basolateral amygdala impair the acquisition of cocaine-seeking behavior under a second-order schedule of reinforcement. Psychopharmacology (Berl) 127:213-224.

Williams BA (1994) Conditioned reinforcement: neglect or outmoded explanatory construct? Psychon Bull Rev 1:457-475. 